research was as follows. A few novel Drosophila homeobox clones had been isolated, and one of these was defined as a $3^{\prime}$ exon of the Ultrabithorax (homeotic) gene. All the novel clones mapped to cytogenetic regions that were known to contain the two homeotic gene clusters in flies. The transcripts encoded in these clones were expressed in unique, homeotic-like stripes on the anteroposterior axis of developing embryos. So, at the time the 1983 Garber paper was written, it was known in Gehring's lab (but only retrospectively) that Garber's band was not an artefact.

It is always possible that Gehring sensed or knew in 1982 that Garber's band was a crucial clue which should be the basis of further investigation. However, to our knowledge no one heard any such suggestion, nothing was done about it, and it did not spark the crucial experiments on the homeobox sequence in Antennapedia and other developmental control genes.

\section{William McGinnis}

Department of Biology 0349, University of California, San Diego, 9500 Gilman Drive, La Jolla, California 92093-0349, USA

\section{Peter Lawrence}

Medical Research Council Laboratory of Molecular

Biology, Hills Road, Cambridge CB2 2QH, UK

1. McGinnis, W. \& Lawrence, P. A. Nature 398, 301-302 (1999).

2. Garber, R., Kuroiwa, A. \& Gehring, W. J. EMBO J. 2, 2027-2036 (1983)

3. McGinnis, W., Levine, M. S., Hafen, E., Kuroiwa, A. \& Gehring, W. J. Nature 308, 428-433 (1984).

\section{Longevity - does}

\section{family size matter?}

\section{Sir - Rudi Westendorp and Thomas} Kirkwood ${ }^{1}$ conclude that women who live longer have fewer children. This can be ascribed almost entirely to an increase in the proportion of childless women in higher age groups. For those women that have children, the mean number of children increases gradually, with a maximum in the 71-80-year-old group, followed by a slight downward trend which is not significant (Table 1).

The overrepresentation of childless women in high age groups suggests that giving birth and raising children shortens life expectancy. But, once you have children, the number you have makes no difference to your life expectancy. Therefore, it is not a matter of reduced fertility, but a case of 'to have or have not'.

\section{Toon Ligtenberg, Henk Brand}

Department of Oral Biology, Academic Centre for

Dentistry, van der Boechorststraat 7 ,

1081 BT Amsterdam, The Netherlands

Westendorp and Kirkwood reply - We found that aristocratic women had low average family sizes, the reasons for which are discussed by Jim Cummins ${ }^{2}$. In these circumstances, any impairment of fertility is likely to result in an increased likelihood of remaining childless. Excluding childless couples from the analysis is therefore counterintuitive. In our opinion, the data from the British aristocracy do not support Ligtenberg and Brand's conclusion that "once you have children, the number you have makes no difference to your life expectancy".

A study $^{3}$ of 822,593 women from the Norwegian census of 1970 found that, among post-menopausal women, those with larger numbers of children (more than four) also had higher mortality rates. This is consistent with our finding of a negative association between longevity and reproductive success; furthermore, it suggests that family size does matter.

In his News and Views article about our paper, Daniel Promislow ${ }^{4}$ suggested that environmental, rather than genetic, factors might explain the trade-off between longevity and reproductive success, which we showed was similar for women and for men. For example, a large family might increase environmental stress and mortality risk for both parents. If this was the case, spouses' lifespans should be correlated. We found a statistically significant correlation, but it accounted for only $2 \%$ of the variance in age at death. The weakness of this correlation argues strongly against environmental factors playing a major role in the trade-off, and supports the hypothesis that genetic factors are important.

\section{R. G. J. Westendorp ${ }^{\star} \dagger$, T. B. L. Kirkwood $\dagger$}

* Section of Gerontology and Geriatrics, Department of General Internal Medicine, and Clinical

Epidemiology, Leiden University Medical Centre CO-

\begin{tabular}{|c|c|c|c|}
\hline Age at death & Proportion childless & $\mathrm{Nu}$ & r of children \\
\hline (years) & & mean for all women & mean for women having children \\
\hline$<20$ & 0.66 & 0.45 & 1.32 \\
\hline $21-30$ & 0.39 & 1.35 & 2.21 \\
\hline $31-40$ & 0.26 & 2.05 & 2.77 \\
\hline $41-50$ & 0.31 & 2.01 & 2.91 \\
\hline $51-60$ & 0.28 & 2.4 & 3.33 \\
\hline $61-70$ & 0.33 & 2.36 & 3.52 \\
\hline $71-80$ & 0.31 & 2.64 & 3.83 \\
\hline $81-90$ & 0.45 & 2.08 & 3.78 \\
\hline$>90$ & 0.49 & 1.80 & 3.53 \\
\hline
\end{tabular}

P, PO Box 9600, 2300 RC Leiden, The Netherlands $\dagger$ Biological Gerontology Group, Department of Geriatric Medicine and The School of Biological Sciences, University of Manchester, 3.239 Stopford Building, Oxford Road, Manchester M13 9PT, UK

1. Westendorp, R. G. J. \& Kirkwood, T. B. L. Nature 396, 743-746 (1998).

2. Cummins, J. Nature 397, 557-558 (1999).

3. Lund, E., Arnesen, E. \& Borgan, J.-K. J. Epidemiol. Community Health 44, 237-240 (1990).

4. Promislow, D. E. L. Nature 396, 719-720 (1998).

City dwellers must share blame on biodiversity

Sir - In your editorial on the debate over genetically modified foods, you say "the steady reduction of biodiversity remains a silent witness to the potential of modern agriculture to inflict damage on the environment and the wildlife it supports" (Nature 398, 639; 1999). It is unfair to attribute solely and without qualification to agriculture an effect that is correlated with a whole raft of land-use changes and also with climate change.

Many farmers take great care over the countryside. You can also argue that city dwellers contribute to the reduction in biodiversity by demanding more housing development, more motorways, and so on. A. J. Murdoch

Department of Agriculture, University of Reading, Earley Gate, PO Box 236, Reading RG6 6AT, UK

\section{Biblical answer to} \section{cooking up pi}

Sir - In the News story about scientists' response to creationists, the scientists "comment that the Bible says that $\pi$ is 3 , not 3.14” (Nature 398, 453; 1999).

The biblical verse quoted (1 Kings 7:23) reads in part: “...measuring 10 cubits from rim to rim... It took a line of of 30 cubits to measure around it". Indeed, 30/10 equals 3, but further on in verse 26 it says: "It was a handbreadth in thickness.... Assuming that a cubit measured 18 inches and a handbreadth 3 inches, the inner diameter of the bowl would be 174 inches $(10 \times 18$ $-2 \times 3)$, and the inner circumference would be 540 inches $(30 \times 18)$. This yields a value for $\pi$ of $540 / 174$ or 3.10 . This is about a 1 per cent error from the typical value for $\pi$ of 3.14. Although we do not know the exact length of a cubit or a handbreadth, this result is very close to the actual value of $\pi$.

\section{Kevin Peil}

Reactor Engineering Group, Dow Chemical

Company, Midland, Michigan 48674, USA 